\title{
Changes and Perspectives in Food Studies
}

\author{
Elisabeth Dumoulin ${ }^{\mathrm{a}}$ \\ a AgroParisTech, UMR 1145, 1 avenue des Olympiades, F-91300 Massy, France \\ elisabeth.dumoulin@agroparistech.fr \\ TEL: +33-1-69935015 \\ FAX: $+33-1-69935185$
}

Received: 24 October 2011; Published online: 18 October 2012

Invited paper from the $2^{\text {nd }}$ International ISEKI_Food Conference 2011

\begin{abstract}
Food Studies represent the bases for multidisciplinary knowledge in food science, food engineering, food management, and how to use these scientific bases in a food worldwide context. Teaching and learning must be adapted to the new students, to the new tools, considering the cost of studies and equipment. The international availability of raw materials, the diversity of cultures, tastes and habits must be taken into account in the controlled food processes. Food engineering must be taught with reference to nutrition, health and security, but also to packaging, logistics, international rules, management of water, energy, wastes and cost. So how do we teach the present and future food engineers, to help them to acquire and build their own knowledge, to develop curiosity, an open mind and team work? How do we teach them to use, in an efficient way, computers, data bases, the internet, but also to learn and practice in the lab, on pilot equipment, in the plant during long internships? How do we give them the desire to conceive, to create, to manage, to communicate and to continue to learn during their professional life? International networks of universities, with associated people from research and industry, with teachers in elementary and secondary schools, with students, represent a main factor for reciprocal knowledge and exchanges, to preserve and use diversity to develop new ideas for teaching and learning. The objectives are to contribute to the development of our society, to feed in an harmonized way the world made of human beings, consumers, and workers in industry, research and universities.
\end{abstract}

Keywords: teaching, learning, food process, studies

\section{Introduction}

The objectives of Food Studies at university level are to give the tools to human beings, to do their job in the best conditions first/mainly where they live, without ignoring the rest of the world, by contributing in their own way to the progress, especially in relation with food, food industry and consumers. The world is made of different people and cultures, and food may represent either a need to survive, a solution to problems of malnutrition or a kind of medicine for wellbeing, nutrition and health. In our world, references and behaviour, knowledge and writing are changing: with computers and the Internet, information and knowledge are available at any moment, replacing many printed documents, facilitating instant communication between people. The role of family has also changed, and there is permanent contact between friends, parents and children, wherever they are (almost) with no time/delay to think.

In this context, our permanent questions as teachers are:

- How to keep the "human contact" between parents/teachers and children/students? 
- What is "Education"? What is the role/job of teachers during studies?

- What is the role of engineers/researchers (and other jobs) in the food sector?

\section{Food industry trends}

The question for the food industry is: how to feed a growing planet? By 2045, the earth's population will likely have increased from 7 to 9 billion people, in a global context of climate change, with a limited amount of drinkable water and land to cultivate. Some experts say that global food production will have to double (Feigl, 2011). Which food production should feed the world, the rich and the poor, the well nourished and the people with not enough food? In countries with famine and malnutrition, the lack of refrigeration and cold installations leads to $70 \%$ of production losses. In tropical countries a problem to solve as serious as water should be a better valorisation of agricultural resources (Gac, 2011). We must adjust diets, produce more food, increase research in productivity and reduce waste between field and fork. In all cases, quantity, quality and safety are the keywords.

The consumers and places to consume are various: adults, children, the elderly; sports events, restaurants, hospitals, etc. The lifestyle in developed countries is changing to "more and more cooking at home made by assembling various elements prepared by the food industry". The cultures, tastes and habits are different in each country for economical reasons, religion and mode of life. The main general goals are to design, formulate and build food products properties and to know how to preserve them.

In 2012 , the complexity of controlled food processes is continuously increasing:

- Diversity and quantity of products meaning flexibility of lines;

- Safety, security along the chain (cold chain, storage, packaging);

- Continuous process improvement, with progress in equipment, measurements, renovation of products, trying to get better un- derstanding by research, modelling (Trystram, Perrot, \& Trelea, 2011);

- New product development to improve quality/security, to attract consumers;

- Costs of goods which must be optimized;

- Sustainability with all considerations of environment, limitation of impacts, selection of raw materials. We observe more automation, with standardisation of quality, with optimisation and global supervision. It leads to a better control of consumption of energy and water (choice of process, recycling, cleaning).

These aspects are similar within big or small companies. In the European Union, small and medium enterprises (SMEs) of $<50$ people represent $\sim 90 \%$ of food companies.

As an example, 50 years ago, raw materials varied from region to region within the same country. Then, we observed an increase of production and standardisation/automation. Nowadays, a new variability has appeared with raw materials coming from around the world, during any season. The international availability of raw materials may be positive: if for example one local raw material is missing because of the dry weather in Europe, it could be imported from South America. But if this raw material shows different characteristics with consequences for the formulation, then the process needs to be adapted, and in the end the production is saved!

The production line is so complex that it means many scientific disciplines are required to be taught in Food Studies to prepare the future engineers (Figure 1).

If we consider Unit Operations, the list is long according to the kind of product/structure to build, to the different treatments from the raw materials through to the food to be consumed, including biochemical and microbiological reactions:

- Handling, weighing, grinding, sorting, packaging;

- Agitation, mixing, emulsification, foaming; 


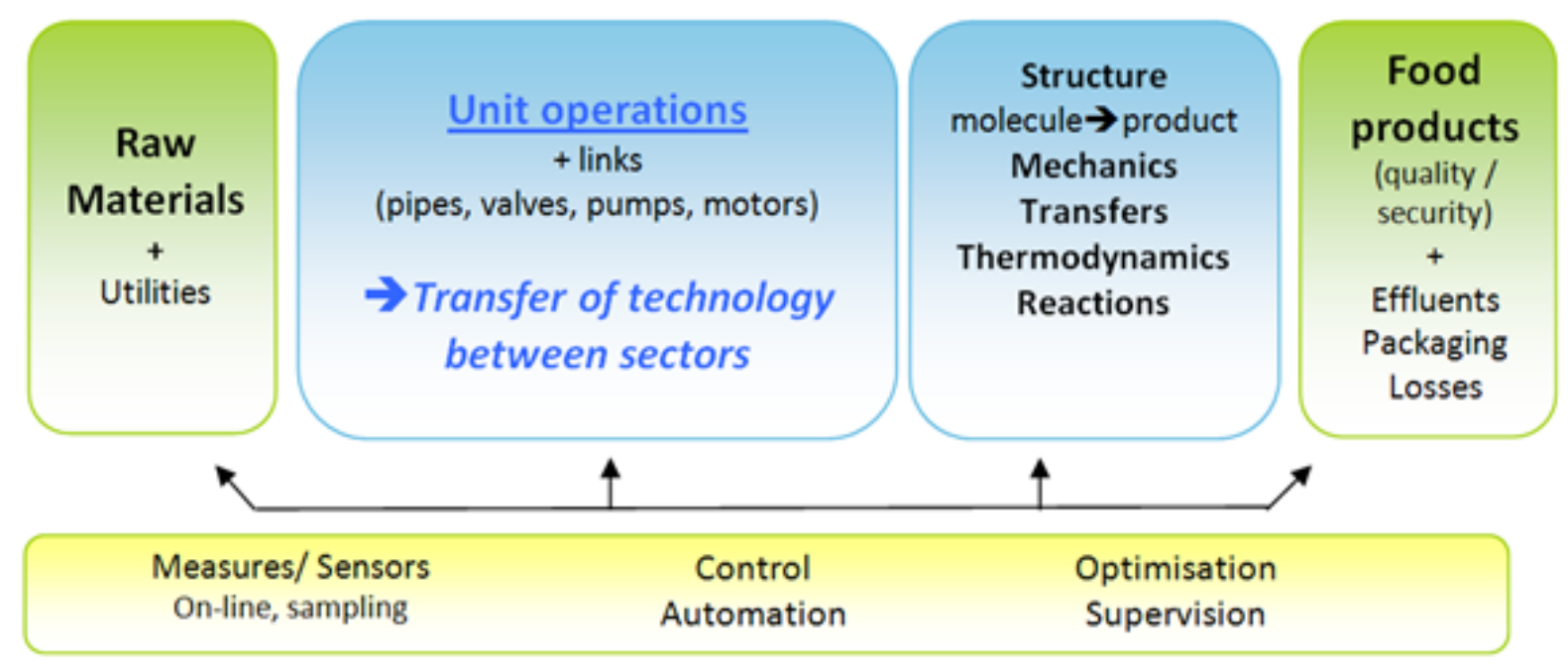

Figure 1: Scheme of food production line

- Decantation, centrifugation, filtration, membrane separation, extraction by pressure;

- Heating, cooling, refrigeration, freezing, pasteurization, sterilization;

- Evaporation, distillation, solvent extraction, chromatographic techniques;

- Drying, frying, cooking, cooking-extrusion, dehydration-impregnation. What is interesting in teaching Unit Operations is the possibility of transfer of technology between sectors, showing the similarities and the differences in equipment, processing modes and objectives.

\section{The objectives of Food Studies}

\subsection{The content}

Food Studies include two aspects: teaching and learning. The different disciplines (Figure 2) are often taught by different people, in relation to their personal background and research field. As these topics are not independent, it means some necessary exchange between teachers, to have at least a common language (words, units, abbreviations ... etc). We could also say that this avoids repetition, but we (teachers) know that "to repeat things" is part of teaching especially if it is said in two different disciplines, in a different context, by two different speakers, where it may be positive for the students to establish links between different aspects.

Besides basic knowledge in Food Science and Technology, students must also acquire, for their future jobs:

- the ability to work in an interdisciplinary team, to be exposed to diversity and multiculturalism;

- the capacity to analyse and synthesize, to put knowledge into practice;

- the capacity to generate new ideas, to adapt to new situations, to learn;

- the critical and self-critical abilities, selfevaluation, decision-making;

- the knowledge of a second language;

- the ethical commitment, interpersonal skills;

- the ability for oral and written communication in the native language;

- and also research skills ... 
In reality if we ask food engineers/professionals about their job and their daily actions, the answers are: to manage people, teams, to supervise production line, to solve problems, to know what/who to ask, to face competition. More generally they must be able to analyse a situation. Their work in order of importance is budget, international, team management, project management, and technical expertise. Food engineers may work in a foreign country (with family), and they easily change work/company. The criteria for job choice in order of importance are salary, work, evolution of carrier, place of work, etc. (CEFI, 2010).

\subsection{What to learn?}

Learning means how to think, how to analyze with a critical point of view, how to store useful information (i.e. notes), to pull information together. Which tools are available to develop such knowledge?

In 3-5 years of Bachelor-Masters, it is not possible to learn/teach everything, but to acquire a certain expertise and in the end to find a job. The wide area of food production from raw materials to final product should be covered; however to make teaching more efficient school/curriculum need to make choices in the topics proposed. What is important is the mode of working, of thinking, the acquired competencies, and the way these competencies are applied during the studies. It is not necessary for all the universities to have the same mode and content for teaching: they must keep their own identity. We do need certain diversity around the world, based of course in common scientific laws and theories.

Two comments:

- The quality of teaching/learning will be later reflected in the food industry, associated with the personal qualities of the workers during their professional life;

- Learning would be more efficient if the student (later the worker) had always a professional goal. That could contribute to a more positive work atmosphere in the group, and create enthusiasm to work hard to obtain results.

\subsection{The students}

Some characteristics - new or not - are very similar in all countries around the world.

For example, some personal parameters can increase the student's interest in studies and jobs. In Food Studies there is a high proportion of women who are usually interested in studies and in their future job/career. Some students are working during their studies to earn money, giving them less free time to study; and some other students share their study time between university and work periods in a company (official agreement university/company). These students usually have clear objectives, and a more positive attitude which is important for the group and for the teachers!

We can observe multi-tasking skills of young people which represent a new "ability" to use (Serres, 2011)! For example when teaching it is usual to have students listening to the lecture with an open computer linked to Internet, reading and answering SMS messages on the mobile and talking from time to time with the person sitting besides about the next evening event. Some people might say "they do not listen to the lecture!" I really believe that young people are used to doing several things at the same time quickly (zapping) and we must find a way to use this ability!

The great importance of images is a reality (TV, computers, mobiles), and maybe we are not using them enough in teaching. How do we better use the images, even if an image represents a certain interpretation of a fact? In a video on a country we do not feel the heat, the atmosphere, the odours, breath the air, the dust, do not meet the people, the animals. Cooking courses on Internet may represent all aspects as changes of colour, texture, but the smell, the pleasure to do it and the taste is absent. To make images become almost a reality may be part of teaching.

All (any) information is available at any time, on-line on the Internet. Even in primary/secondary school, all is on-line: preparation work, marks, and absences in real time 


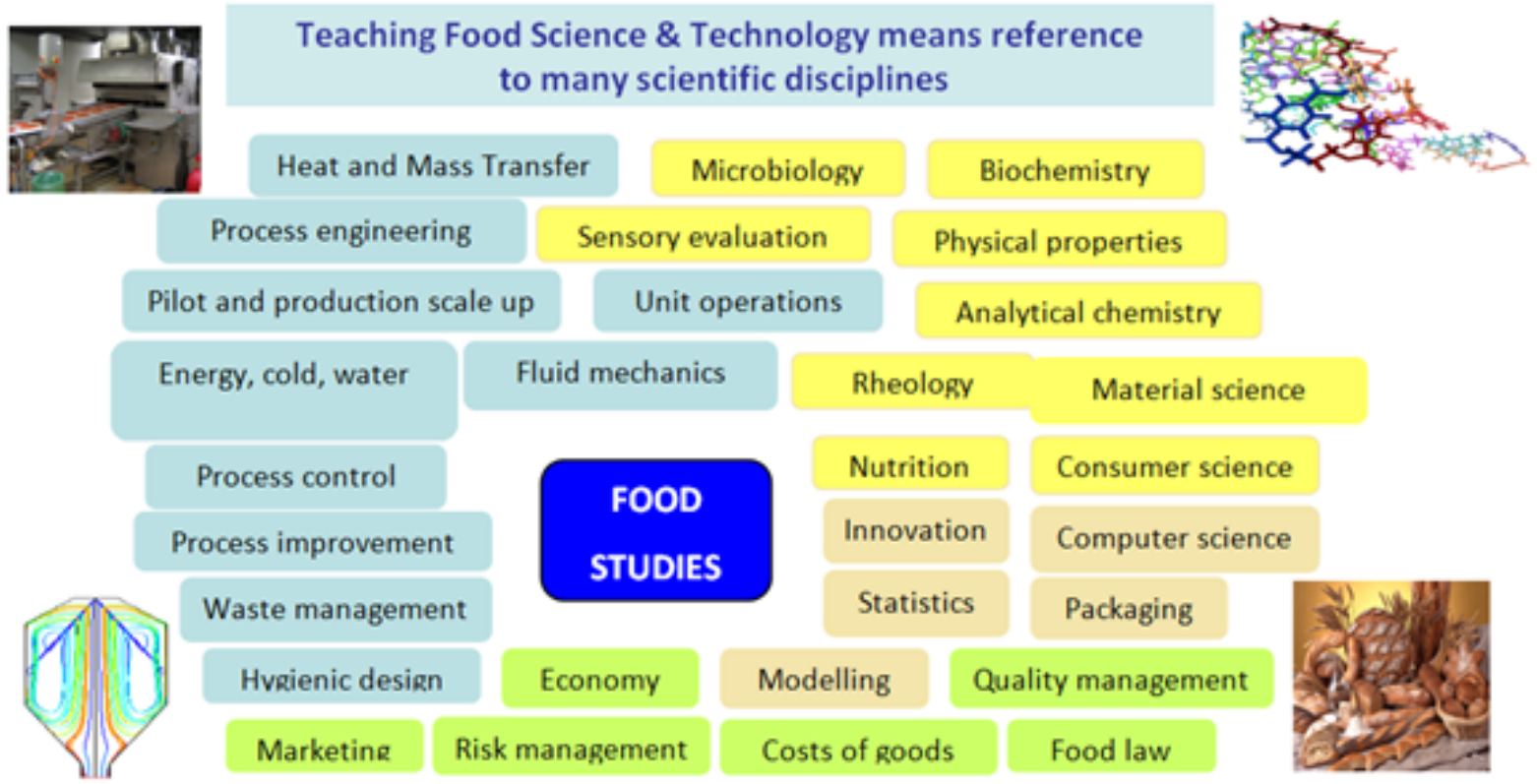

Figure 2: Disciplines involved in Food Studies

(parental contact). No more need of maps to go somewhere, just a good mobile and some time. At any level it is used for evaluation tests, questions on-line and the professor can check who did it, how, when. There is a permanent contact with parents, friends, with family and teachers! The family links have been modified. This is a real big change for society, without knowing the possible consequences. We just can say that it is positive when looking for some information on process, product, on any immediate question, and to have rapid contacts/exchanges with the world.

In this context, we can also add that the students like to search and find information; they have more difficulty to learn, to do this by themselves and to apply it. How do we make them conscious that there is not only one answer to one question, but several elements of answers? Do they know how to work hard to obtain what they want (objectives), and have they an opportunity to feel responsible?

\section{Teaching and learning - The tools}

The following tools are not new (i.e. Walters \& Pawsey, 2011), they are useful and could be examined by teacher teams to improve them, to make them attractive for students, to give the desire to learn, to create some enthusiasm.

\subsection{Courses, lectures}

Courses are necessary to teach the bases. It may be done by teachers, researchers, industry speakers. All have to remember that theory is not a finality, it must be illustrated by examples of applications. Powerpoint presentations are very convenient for speakers, either complete with all details or not complete to give more information during the talk. Courses are put on-line with possible contact with teacher. But students say that it is not enough to learn: therefore printed documents, books and new supports must be created. Probably we do not use enough internet, videos and games simulating reality with scientific comments given by the teachers. 


\subsection{Tutorials, exercises, problems solving activities}

Although it is useful to take time to go further into details, to answer a specific problem, to give examples for illustration purposes, working out real example calculations, they are only possible in small active groups. The presence of teachers able to answer and ask questions is necessary ( $\mathrm{PhD}$ students may help, as it is good teaching training for them).

\subsection{Project-team work (2 to 5-6)}

Topics of interest may be defined and further followed in partnership with teachers, industry, secondary schools. It must be:

- A project feasible for the group (level of competencies required, interest for learning);

- A concrete experience as a team (organisation, sharing opinion and knowledge), with time to ask questions, to give the desire to understand.

In all these activities, courses, tutorials, project, the "teacher" must be able to explain, to listen, to give information, a task which needs efforts, up-dated knowledge and time for the teacher.

\subsection{Practical work in lab, pilot plant}

In Biochemistry, Microbiology and Unit Operations, the benefit of such practice will be maximised if done in small groups (4 to 6 students). It is of course possible to use computers and video to look at industrial applications, to test the effect of parameters, which gives a good approach when the application has been already taught during courses. But it is necessary to practice, to touch, to evaluate: i.e. to measure temperatures (tool, precision), to estimate time, to have an idea of reaction rates, to look and practice on equipment, to see the possibilities and limits of analyses. It gives an opportunity to discover new techniques (analyses), new processes (real or virtual). More generally practicals are tools to acquire notions of time, of working in practice, of cleaning, of validity of results, and to learn rigour. The problem that all universities are facing is the budget necessary to buy and maintain the equipment including technicians and teachers, and enough time needed for students in their curriculum (lectures are often preferred).

\subsection{Internships and visits to plants}

These represent the discovery of industrial environment: a view of the future. A minimum of 3-4 months working in the food industry should be recommended, and included in the curriculum as compulsory, which means agreements with industries and university supervisors. The students will learn about how people work in a factory/lab, how to respect rules in work and time schedule, which can be used further in life, at university. A report and an oral presentation of the work (to a different audience) will validate the time and efforts. Internships and Mobility for part of studies in a foreign country are recommended with a scientific objective, to discover other cultures, and to evaluate personal capacity to do it. Since 1988, various European exchange projects have been successful, being furthermore a real source of worldwide cooperation.

\subsection{Exam, evaluation}

To check the acquired knowledge any type of evaluation is useful to learn for real life: written exams, individual oral examination or on computer, report, oral presentation (to explain clearly); and at any time during lectures, tutorials, or at the end of teaching. The only recommendation is again to provide concrete problems to solve. 


\subsection{Others activities}

The following activities are part of studies and useful for life (professional, association, group, family):

- Team building, team working, team management;

- Communication by sharing personal knowledge, adapting the content to the audience (towards teachers, other students, a wider public audience, colleagues (written, oral));

- Languages are to be developed without limit! Why not work more with language teachers and Masters students. These students come from all around the world, speaking many languages and want to develop in return the local language!

- All topics/information related to the food sector (conferences, exhibitions), and also contacts with former students are essential to confront personal ideas on jobs and career to reality.

\subsection{Place of Research}

For the academics, research represents a breathing air, a renewal of knowledge, a way to see problems in another context. All research projects are sources of facts and data useful for teaching, useful to keep in touch with industry objectives, to cooperate with different teams. Exposure of students, some of whom will be candidates for $\mathrm{PhD}$ studies, to research with multidisciplinary projects during studies, in collaboration with $\mathrm{PhD}$ students and researchers, is the right way to explain and to understand what research is.

\subsection{Others possible studies}

- Open and distance learning, short courses are important elements to develop in a network of universities to put in common experiences of teaching and research;

- Joint Masters and PhD programmes may represent a tool to increase existing links between several universities;
- Continuing education organized by the company, university, association will be useful during working life to learn and to modify career. It is also an opportunity for the worker to meet other people, out of the enterprise. Proposed topics are often related to team and project management, quality and security, scientific and technical;

- Validation of acquired experiences (VAE) for people working in industry represents a possibility to obtain a Diploma recognized in the work place. The candidate must define a project and acquire complementary knowledge if necessary. Universities have a role to play in this process.

\subsection{The role of teachers}

Following what was said previously, to participate actively in all study activities teachers must be competent and enthusiastic! But we also know that for the career development of teachers, research interests (responsibility for Masters and PhD students; active participation in projects; publications, congresses) are seen and considered to be much more important than teaching. At present there is no solution, except hard work.

\section{Role in Teaching}

The students are changing through the years and it is the task of teachers to adapt their teaching to the new students. Their role is:

- to teach the basis, to provide information with different levels to take into account the different backgrounds. Information must be clear, well informed and up-to-date. Here the universities network could be useful for exchange between teachers in the same disciplines;

- to invent new tools for teaching (e.g. virtual games to learn (Singh, 2011). Again the universities network could be useful;

- to explain the mistakes, to push the students to find by themselves, to give the taste of learning; 
- to guide students for their professional project. In some universities, tutoring is organised. It means face to face communication between one teacher and one student (or more) to listen, to exchange. That needs a mutual acceptance, and committed time for both, resulting in better mutual knowledge. A general remark is to try to work in small groups if possible, which means more teachers. In such a way it is much easier for teachers to evaluate the individual student capacities, to identify problems.

\section{Role for Contacts}

Teachers can represent the privileged contact with industry (student training, research, teaching by industry people). They can engage in dialogue and know about the problems, the success, the needs of industry, keeping in touch with former students. They are the best people to establish exchanges/contacts with secondary schools close to university. These schools are the place where the future students are formed, where they will acquire the desire to learn about science.

\section{Role for Evaluation}

After teaching, it is necessary to prepare evaluation tests to check knowledge. Modes of evaluation are chosen by the teacher as a function of the mode and content of teaching. In the end the acquired knowledge will lead to diplomas.

\subsection{In summary}

Teaching/learning contribute to prepare students for jobs/careers in Society. With their own personality, students may acquire different qualities through education (Figure 3). At the end of their Food Studies, the graduated students ideally should know about (and have visited) most of the production lines of main food products not only Fick or Fourier laws, enthalpy, entropy, glassy state, etc. The teachers must have a good knowledge about factories in their field of teaching. A professional experience in industry and in research should be very positive. All the described tools are similar for all teachers: they can be discussed, exchanged, improved per discipline, and (re)discovered. There is a clear need of exchange between teachers in universities and between universities through meetings, networks, etc.

\section{A network of universities}

Since 1988, many university networks have been built, especially in Europe. Meetings were facilitated by some financial help, very useful to develop mutual knowledge. Exchanges also were existing around the world through research teams, personal contacts, students doing their $\mathrm{PhD}$ studies in foreign countries, etc. The International ISEKI_Food Network and the ISEKI_Food Association are examples of what was built along the years around Food Studies: they were the organizers of the International ISEKI_Food Conference in Milan in 2011, where this paper was first presented.

\subsection{The European Socrates-Erasmus Thematic network ISEKI_Food}

Based on Education Institutes, this network includes representatives of all partners from the food world: research institutes, industries, students, professional associations and consumers (Figure 4).

Two complementary projects existed in 2011 (www.iseki-food.eu):

- ISEKI_Food 3 with 96 partners in enlarged Europe (30 countries)

- ISEKI_Mundus 2 with 53 partners in 5 continents (30 countries)

The institutions members represent more than 120 degrees (Bachelor, Higher diploma, Masters), with more than half of them using the common European Credit system (ECTS) for evaluation. That is a practical tool for validation of student stays/courses in partner universities. These degrees represent a large diversity in sectors and areas of employment:

Sectors Food \& Cosmetics, Pharmaceutics, Trade, Computers, Marketing, etc. 


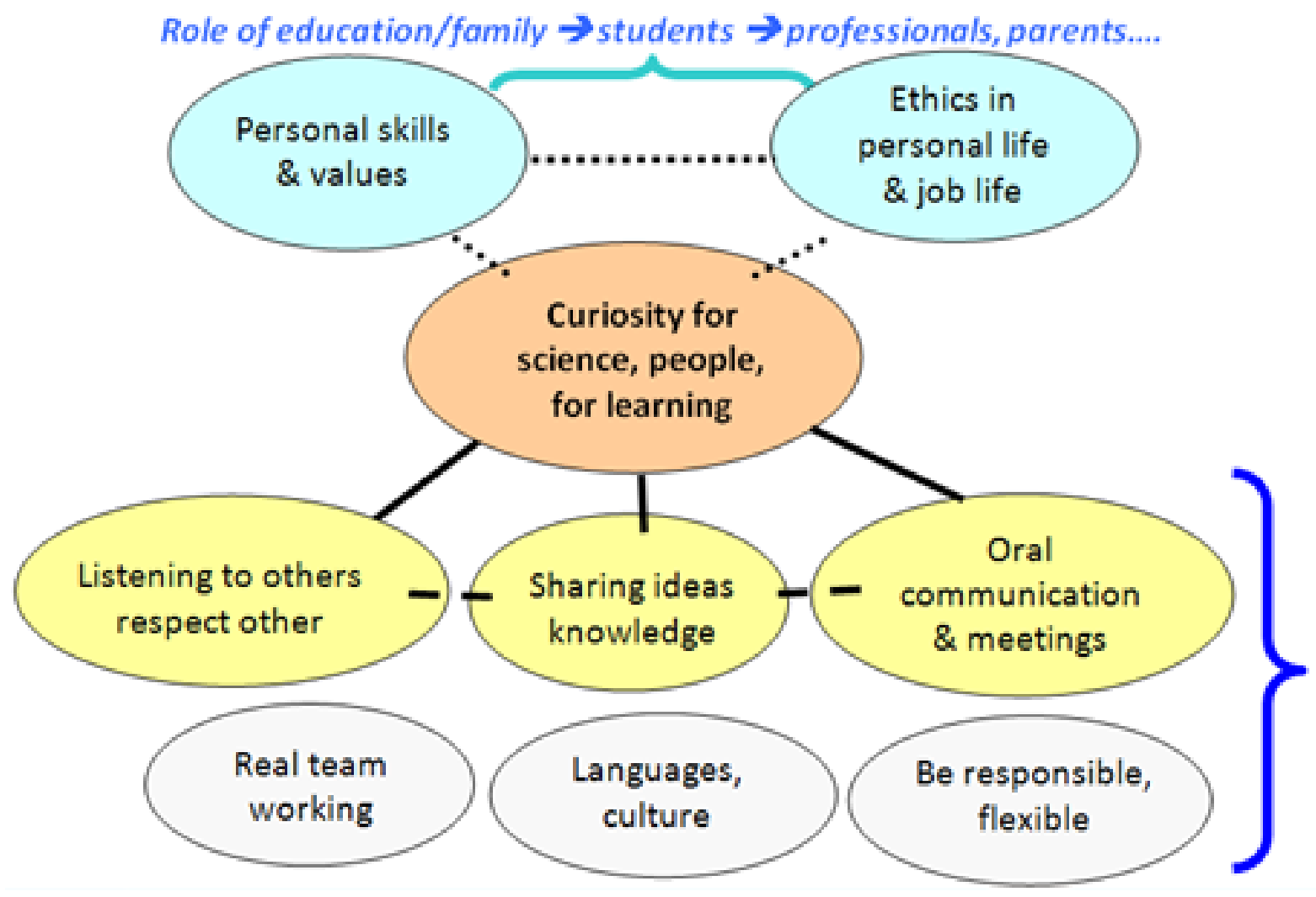

Figure 3: Skills acquired along life

Areas Production, R\&D, Consulting, Quality, Marketing, Trade, Technical Assistance, Informatics. The names of Food Studies degrees differ showing the specialities in each university and country:

Disciplines Food Science, Food Technology, Food Engineering, Food Safety, Food Chemistry.

Sectors Brewery \& Drink Technology, Viticulture \& Oenology, Catering Science \& Food Consumption, Dairy Science, Meat Science, Cereal Technology.

\subsection{Some results, visible and non-visible}

Through the years the main work was about education, teaching, comparing curriculum, devel- oping tools which could be used by each member to improve studies and exchanges:

- Books $(>12)$ written in collaboration with teachers/researchers from different universities represent a unique experience.

- E-learning common courses are in development.

- Data bases on curriculum, pilot equipments, and laboratory equipment.

- Guidelines and standards on minimum requirements in study programmes, and quality assurance (European Quality Accreditation System for Food Studies, EQAS-Food) were developed.

For exchanges and contacts, the existence of the network was very positive for better mutual knowledge of programmes: it was for exam- 


\section{FOOD SCIENCE \&}

TECNOLOGY

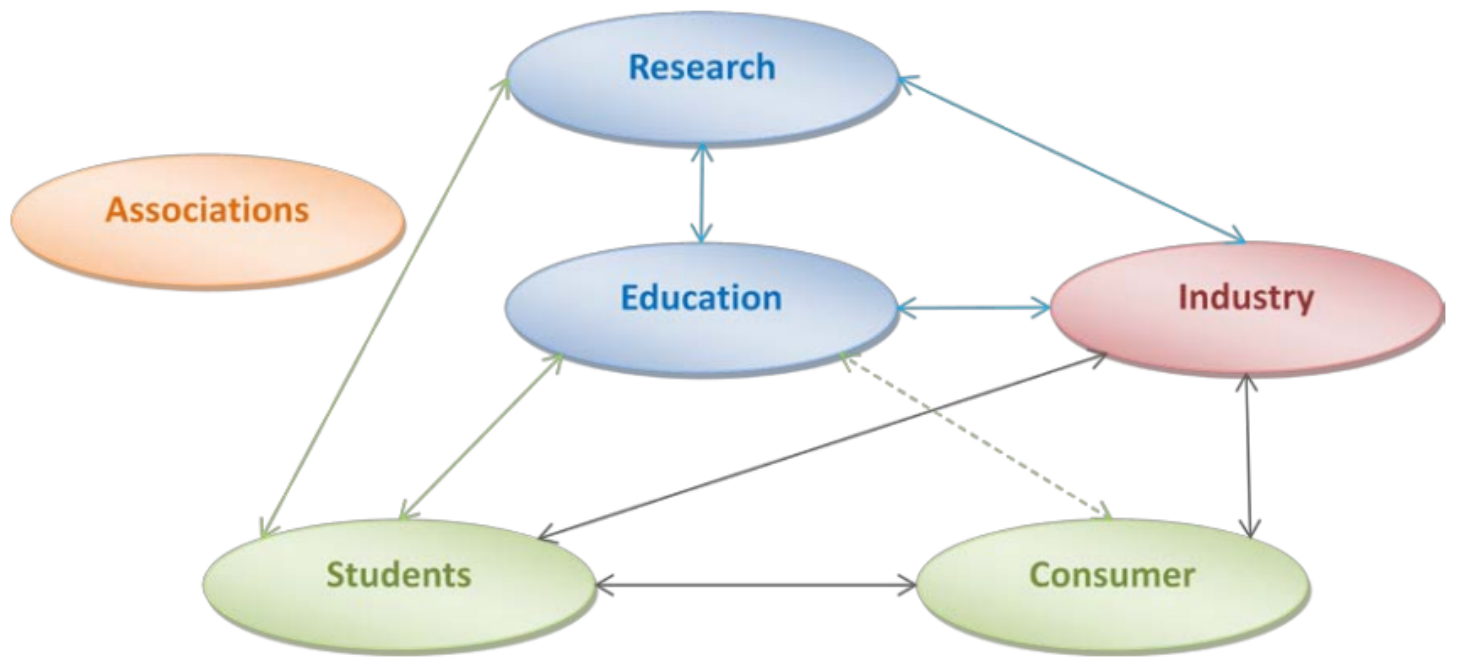

Figure 4: Partners of the ISEKI_Food network

ple easier to develop student/teacher exchanges. For students a training period in another country (university, laboratory or company) represents an opportunity to discover another culture/language and to work in a new environment. The recognition of periods of studies by administration was not always easy because of different contents, other teaching methods. But we worked to improve it, recognising the student efforts to learn. The application of the European credits system ECTS developed during the last years was facilitated because of possible explanations during meetings.

Globally the network represents a real opportunity for contacts between persons:

- Meetings, visits (students, supervision of training, exchanges of teachers). It was possible to visit other campus, to see other equipment and to better understand similitude and differences;

- Congresses, workshops were organised on education \& research;
- Sabbatical periods for teachers were possible! We could imagine developing such a sabbatical period in the Industry: it should be a great experience for most teachers!

Among the members of the network it was possible to find the right partners to develop new projects, new groups in education and research. The internationalisation of the network, using the existing contacts of universities partners was a way to share other cultures, with a similar approach (difficulties and pleasure) in teaching and research.

Because of the need to communicate between all the actors of universities members of the network about education, but also with our partners in research, in industry, we had the idea to create the present International Journal on the Internet.

In summary the ISEKI_Food Network is the sum of individual partners with their own personal experience (varied and complementary) and their willingness to share, to change, to innovate by meeting, working, by doing things together. It is a place to listen, to learn from the

IJFS | October 2012 | Volume 1 | pages 211-221 
others and to get the desire to change something, to know each other not only in a virtual world. It represents an opportunity to share successful experiences, or to test a new idea to develop by the group, and to initiate new projects. A network is a "human data base" and "a huge machine" for "ideas innovating and manufacturing". It needs energy (renewable!) from all members to give results with the best success!

\section{Conclusion}

Teaching represents a virtual and a real world, which must be adapted to the changing world. We must find the ways, with new methods.

Some points seem to be important:

- Necessary to teach/acquire bases (key points), developed in applications in small student groups: invent new supports, new teaching techniques (including teacher training).

- If possible teachers must have a professional experience in food industry for concrete and up-to-date examples in teaching, and to be a link between university and industry.

- The role of languages is important, in disciplines, in teaching and in work.

- Training periods in industry, contacts with food professionals and former students are essential for students to discover the industrial environment.

- Practical work (small groups) with equipment and products represent the key of learning. To reduce the costs we must find a way to share equipment/labs between universities - and why not also with industries?

More generally for all people, access to information with "Internet for all" is positive. How to keep a critical eye when looking for answers, doing literature review, to judge the quality of information?

And how to push the students to have a professional project?

Teaching and learning are two changing worlds full of perspectives. There is still some work to do with colleagues in the networks, not only to produce deliverables, to disseminate, but to discover, propose/discuss solutions again and again, to innovate! We need motivated, curious, enthusiastic, open minded students and teachers working together with the help of the researchers and industry people, of the primary, secondary schools and colleges, to participate in the harmonious development of our society, to feed in an harmonized way the world made of human beings, consumers, of workers in industry, research and universities.

\section{Acknowledgements}

Many thanks to all, students, colleagues, teachers, industry people, friends, who accepted to give me their opinion, ideas, feelings during interviews - this is also their life!

\section{References}

CEFI. (2010). Observatoire de l'emploi des ingénieurs diplômés. Comité d'études sur les formations d'ingénieurs, 21ème Enquête CNISF, Paris. Retrieved from http://www. nanotechproject.org/inventories

Feigl, A. (2011). How to feed a growing planet. National Geographic. 220(1):30-31.

Gac, A. (2011). Développement durable, ditesvous?. Revue Générale du Froid, 1117:28.

Serres, M. (2011). Eduquer au XXIe siècle. Le Monde.

Singh, R. (2011). Food engineering education in the digital age. Proceedings ICEF11, Athens, Vol.1, 799-800.

Trystram, B., G.and Broyart, Perrot, N., \& Trelea, C. (2011). New modelling stakes and tools to face complex food systems. Proceedings ICEF11, Athens, Vol.1, 321-322.

Walters, M., \& Pawsey, R. (2011). Personal skills: an integrated component of food science courses. application of the "active learning" paradigm. Socrates European Thematic Project on Food Studies. Pub. Dept Food Science, College Dublin, 226p. 